\title{
Evaluation of Antibacterial Activity, Chromatographic Analysis for Rutin and Quercetin Quantification Using HPLC-UV-Vis from the Hydro-Alcoholic Extract Obtained from Bidens pilosa Linné
}

\author{
Carlos A. Pinilla, ${ }^{\circledR *, a, b}$ Ángela M. López, ${ }^{b}$ Andrés F. Gálvez, ${ }^{b}$ Eduardo J. Corpas, ${ }^{c}$ \\ Milton Rosero-Moreano ${ }^{b}$ and Elena E. Stashenko ${ }^{d}$ \\ ${ }^{a}$ Grupo de Investigación en Efermedades Infecciosas (GINEI), Universidad Católica de Manizales, \\ Carrera 23 No. 60-63, Manizales, Colombia \\ ${ }^{b}$ Grupo de Investigación en Cromatografía y Técnicas Afines (GICTA), Departamento de Química, \\ Facultad de Ciencias Exactas y Naturales, Universidad de Caldas, Calle 65 No. 26-10, 170004 Manizales, Colombia \\ ${ }^{c}$ Grupo de Investigación y Desarrollo Tecnológico para el Sector Agroindustrial (INDETSA), \\ Universidad Católica de Manizales, Carrera 23 No. 60-63, Manizales, Colombia \\ ${ }^{d}$ Centro Nacional de Investigación para la Agroindustrialización de Plantas Aromáticas y Medicinales Tropicales \\ (CENIVAM), Centro de Investigación en Biomoléculas (CIBIMOL), Universidad Industrial de Santander, Carrera 27, \\ Calle 9, 680002 Bucaramanga, Colombia
}

\begin{abstract}
Novel and miniaturized technique, a dynamic sonication-assisted solvent extraction before the analysis by high performance liquid chromatography-ultraviolet visible (HPLC-UV-Vis) for isolation, identification and quantification of rutin and quercetin metabolites in alcoholic extracts from Bidens pilosa Linné, was developed. The results showed that the flowers have a greater quantity of both analytes than other parts of the plant (e.g., leaves, stem and roots), the results were corroborated by liquid chromatography-mass spectrometry (LC-MS). In addition, the developed extraction technique against traditional methods for metabolites extraction such as solid-liquid extraction, Soxhlet and rotating-disk sorptive extraction was compared. Under optimal conditions of extraction such as $0.3 \mathrm{~mL} \mathrm{~min}^{-1}$ of solvent flow, ethanol:water (1:1) as solvent type and $0.5 \mathrm{~g}$ of sample amount, it was possible to reach $85 \%$ of recovery percentage of target analytes and a limit of detection close to $0.1 \mu \mathrm{g} \mathrm{g}^{-1}$ with a linear range of $50-400 \mu \mathrm{g} \mathrm{g}^{-1}$ were also obtained. Finally, the antibacterial evaluation of the flower extract of Bidens pilosa Linné, obtained under above optimal conditions against Gram-positive bacteria, was performed. The higher values of the inhibition diameters when using $1000 \mathrm{mg} \mathrm{L}^{-1}$ and significant differences among Staphylococcus aureus, Bacillus cereus, and Listeria monocytogenes were observed. The tests were performed with different microorganisms inoculated from three different absorbance levels ( $0.05,0.5$ and 0.1 absorbances), at a lower absorbance of these microorganisms in the growth medium used for evaluating the inhibitory effect of the $B$. pilosa Linné extract, when using this extract at the concentrations of 500 and $1000 \mathrm{mg} \mathrm{L}^{-1}$, statistically higher inhibition diameters were noticed.
\end{abstract}

Keywords: Bidens pilosa L., quercetin, rutin, dynamic sonication-assisted solvent extraction (DSASE), antibacterial activity, LC-MS orbitrap, Staphylococcus aureus, Bacillus cereus, Listeria monocytogenes, sample preparation, greener solid-liquid extraction

\section{Introduction}

Natural products and the use of their extracts or metabolites such as phytotherapeutics have been put forward as the early stages of humanity. According to the World Health Organization (WHO) ${ }^{1-3}$ approximately $80 \%$ of the

*e-mail: cpinilla@ucm.edu.co population use herbs for primary health care. In developing countries, the widespread use of traditional plant-based medicine is related to its accessibility and affordability. ${ }^{4}$ For example, the indigenous communities of South America prepare infusions, extracts, compresses, and pastes or poultices; and have used different methods for the treatment, use, and plants collecting. ${ }^{5}$

The traditional uses of different plants along with their 
ethnomedical uses are well established and recognized by the ancestral culture of South America. This particular research focused on the study of extracts obtained from Bidens pilosa L. It was classified by Carl von Linné in 1753 A. D. Bidens pilosa L. properties and its pharmacological actions are related to intestinal injury, ${ }^{6}$ antibacterial, ${ }^{7}$ antioxidant ${ }^{8-10}$ and immunomodulatory, ${ }^{8}$ antifungal, ${ }^{11}$ anti-inflammatory, ${ }^{11}$ hepatoprotective, ${ }^{11}$ and antimalarial ${ }^{11}$ in vitro activities, and also in the treatment of liver disease, hepatitis, diabetes, sore throats, tonsillitis, pharyngitis, urinary tract infections, vaginal discharges, and gastric ulcers. ${ }^{12-16}$

Studies ${ }^{17,18}$ conducted on Bidens pilosa L. showed a wide variety of secondary metabolites related to flavonoids, terpenes, phenylpropanoids, phenolic acids, coumarins, and porphyrins regarding Bidens pilosa $\mathrm{L}$., various polyphenols are produced by means of shikimic acid and studies have been made about rutin and quercetin flavonoids (Figure 1). These compounds occur in structures in the form of glycans such as rutin or aglycone like quercetin. Thus, for the quantification of aglycone type flavonoids, as in the case of quercetin, a hydrolysis reaction that guarantees its determination is required..$^{19,20}$<smiles></smiles>

Quercetin

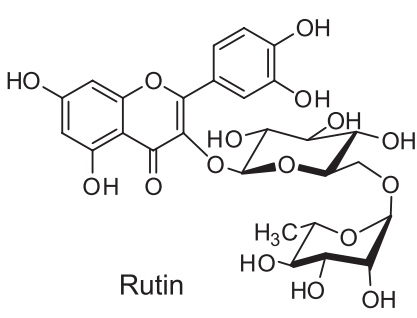

Figure 1. Target metabolites present in B. pilosa L.

The extracts have been processed with solvent (liquid) extraction way to obtain active principles with extractions such as Soxhlet and solid-liquid extraction (SLE). ${ }^{21-24}$

The main methods reported ${ }^{3}$ used as solvent ethanol, mixture of water and ethanol, and only water in the case of infusions. For studies of methodologies that contribute to the selective extraction of metabolites, the use of modern extraction techniques related to efficiency, low cost, green techniques, and the pre-concentration of analytes are put forward. ${ }^{25-31}$ Among these processes and as representatives for the green and modern extraction methodologies, in this work two new miniaturized techniques were assayed and developed: the rotating disk sorptive extraction (RDSE), which has the advantage of having a greater surface area, simple process and stirring technique, resulting in the reduction in the amount of sample and solvent, ${ }^{32-34}$ and the dynamic sonication-assisted solvent extraction (DSASE) that uses a stainless steel cell that contains the sample and requires to optimize the following parameters: sample amount, flow, and solvent type. ${ }^{35,36}$ Both were evaluated by high-performance liquid chromatography-ultraviolet visible (HPLC UV-Vis). ${ }^{37}$

Studies ${ }^{38-40}$ with extracts of the plant obtained by traditional methods such as SLE and Soxhlet have reported antibacterial properties against Gram-positive bacteria; resulting in an efficient antibacterial extract opposing Gram-positive bacteria.

The aims of this work consisted in the validation of a chromatographic method using UHPLC-UV-Vis, the optimization of the efficient DSASE extraction of rutin and quercetin, its subsequent quantification at different parts of the plant, and the antibacterial evaluation of the extract against Gram-positive bacteria. This research dealing with natural extracts, green methodologies, and phytotherapeutic properties raises the opportunity and potential of valuable plants that have been great ethnomedical uses.

\section{Experimental}

\section{Plant material}

The vegetable material was collected in the southern part of the city of Manizales at a height of 2089 masl (meters above sea level) $\left(5^{\circ} 02^{\prime} 00^{\prime \prime} \mathrm{N} 75^{\circ} 27^{\prime} 46^{\prime \prime} \mathrm{W}\right)$ in the Enea neighborhood, Manizales (Caldas, Colombia). The verification of its taxonomic identity was carried out in the University of Caldas herbarium and listed with the deposit number 10695; FAUC 2017, Manizales. The plant material for research analysis was collected in the period between July 2018 until June 2019. It corresponds to wild plants located on the roadside and the collection of the samples was always carried out in the morning hours. The treatment of the specimen after collection of the sample was as follows: drying was carried out for $120 \mathrm{~h}$ in an oven at $38{ }^{\circ} \mathrm{C}$ and it was homogenized with a mill that had a $1 \mathrm{~mm}$ filter.

\section{Materials and methods}

The following equipment were used: a 1093 Cyclotec Sample Mill with a $1 \mathrm{~mm}$ filter (Fisher Scientific, FOSS Analytical, Waltham, MA, USA), Thelco Laboratory furnace 3500 (Thermo Scientific), automated Soxhlet, Büchi Extraction system B-811, BÜCHI Labortechnik AG, Switzerland. Reference pump, PU-2089 Quaternary Gradient HPLC pump, JASCO (Leco), USA. Branson 2510-DTH reference ultrasound bath with a stainless steel extraction cell with an internal capacity of $3 \mathrm{~mL}$ developed by the research group GICTA, Universidad de Caldas, 
with alliance of the Servicio Nacional de Aprendizaje (SENA), Caldas, in the dependency of the Workshop of Automation and Mechanics. The solvents used were Scharlau chromatographic grade methanol and ethanol, rutin and quercetin standards with a 95\% Sigma purity level imported by Outsourcing S.A.S. (Manizales, Colombia). A Thermo Scientific UHPLC UltiMate UV-VIS 3000 with Chromeleon 7.2 software was employed (Thermo Fisher Scientific, Waltham, MA, USA), and the column used was a Thermo Scientific Hypersil GOLD C18 $(150 \times 4.6$ mm ID, $5 \mu \mathrm{m}$ particle size).

The liquid chromatography-mass spectrometry (LC-MS) analysis was done at the Research Center for Chromatography and Mass Spectrometry, CROM-MASS, of the School of Chemistry in the Faculty of Sciences at the Universidad Industrial de Santander. The Thermo Scientific Dionex Ultimate 3000 UHPLC LCMS system equipped with a quaternary RS series pump and TCC-3000RS column compartments with a WPS-3000RS auto-sampler and a fast separation PDA detector controlled by Chromeleon 7.2 software (Thermo Fisher Scientific, Waltham, MA, USA and Dionex) was used. The chromatographic system was coupled to an electrospray ionization source (HESI II). Nitrogen used was produced by generator (purity $>99.95 \%$ ) Genius NM32LA (Peak Scientific, Billerica, MA, USA). The mass calibration for Orbitrap ${ }^{\mathrm{TM}}$ was performed in negative and positive modes.

The microorganisms used were as follows: Staphylococcus aureus subsp. aureus (ATCC 25923), Listeria monocytogenes (ATCC 13932) and Bacillus cereus (ATCC 0299). Brain heart infusion broth (BHI), and enrichment broth (Scharlau) were used as culture medium. Baird Parker, Palcam and Bacillus cereus agars for Staphylococcus aureus, Listeria monocytogenes, and Bacillus cereus, respectively (Agars Thermo Scientific TM Oxoid ${ }^{\mathrm{TM}}$, Waltham, MA, USA), were used as bacteriological agars.

\section{Extraction procedures}

\section{SLE and Soxhlet}

The SLE was performed using a sample of $0.5 \mathrm{~g}$ from the aerial parts of the plant (flowers and leaves) utilizing a solvent with a proportion of $5 \mathrm{~mL}$ ethanol:water (80:20) during $24 \mathrm{~h}$ to carry out the extraction, followed by subsequent filtration and extract acid hydrolysis. The Soxhlet extraction ${ }^{41}$ was made using $7 \mathrm{~g}$ of the aerial parts of the plant (flowers and leaves) and the standard Soxhlet programming method, employing 4 cycles for rinsing and $10 \mathrm{~min}$ for washing, using only the lowest evaporation temperature of the solvent, employing $70 \mathrm{~mL}$ of the ethanol:water ratio (80:20), for a total extraction time of $50 \mathrm{~min}$.

\section{RDSE and DSASE}

The miniaturized techniques in extraction processes for solid type matrices were evaluated, one of them being the micro-extraction technique that has been developed by Richter and co-workers. ${ }^{32,33}$ This consists in the RDSE extraction in modified way, firstly herein reported with a rotating disk of Teflon ${ }^{\circledR}$ in reverse mode which contains a cavity to deposit the sample in which $0.2 \mathrm{~g}$ of the aerial parts of the plant were sprayed, with $5 \mathrm{~mL}$ of solvent ethanol:water (80:20) and stirred for $30 \mathrm{~min}$ at $1500 \mathrm{rpm}$, until the extract was obtained for subsequent acid hydrolysis. The DSASE exhaustive extraction technique was adapted from López et al. ${ }^{35}$ and Sánchez et al. ${ }^{42}$ In this modification, a stainless steel cell with an internal volume of $3 \mathrm{~mL}$ was used to contain the sample, a $5 \mathrm{~mL}$ volumetric flask was used for the collection of the extract. The variables solvent flow $\left(\mathrm{mL} \mathrm{min}{ }^{-1}\right)$, solvent type and sample amount $(\mathrm{g})$ were used according to previous research ${ }^{36}$ applied to plant-type matrices.

The initial evaluation conditions were as follows:

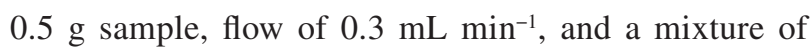
ethanol:water (80:20), $30 \mathrm{~min}$ of extraction time and the obtaining of $5 \mathrm{~mL}$ of the extract for the subsequent hydrolysis.

\section{Acid hydrolysis}

The acid hydrolysis process by using a volume ratio (1:3:3) of the extract: $\mathrm{HCl}: \mathrm{H}_{2} \mathrm{O}$, with $3.5 \mathrm{M} \mathrm{HCl}$ was done. The process was carried out for $1 \mathrm{~h}$ in an ice bath, the liquid-liquid separation was carried out with ethyl ether and the remain extract was washed with distilled water. Finally, a laboratory concentrator RVC2-18 CDplus (Christ, Germany) was used in the organic phase and reconstituted with $100 \mu \mathrm{L}$ in methanol:water (80:20) (HPLC mobile phase). ${ }^{19,20}$

\section{Chromatographic analysis}

The chromatographic methodology was evaluated according to the validation guideline ${ }^{43,44}$ that have already been established. For that purpose, calibration curves for rutin and quercetin quantification were prepared by gravimetric calibration of volumetric standards using an electronic balance in a range between 50-400 $\mu \mathrm{g} \mathrm{g}^{-1}$. The repeatability and reproducibility were analyzed in intra and inter assays by relative standard deviation RSD (\%), limit of detection (LOD) and limit of quantification (LOQ). 
LOD and LOQ were calculated by the ratio $\mathrm{S} / \mathrm{N}=3$ and 10 , respectively, ${ }^{45,46}$ which $\mathrm{S} / \mathrm{N}$ is the signal-noise ratio.

The analysis by liquid chromatography was performed with Ultra-HPLC that has a UV-Vis detector and the column used was $\mathrm{C}_{18}$ of $150 \mathrm{~mm}$; a mobile phase in a gradient mode ramp of 40:60 methanol:water at the start and 60:40 at the end for 10 min running time at a wavelength of $373 \mathrm{~nm}$, a $20 \mu \mathrm{L}$ injection volume, and at a flow of $1.0 \mathrm{~mL} \mathrm{~min}^{-1}$.

LC-MS parameters used a UHPLC C18 column Acclaim $150 \times 4.6 \mathrm{~mm}$ ID, $5 \mu \mathrm{m}$ particle size, (Thermo Fisher Scientific, Bremen, Germany), operated at $25^{\circ} \mathrm{C}$, the mobile phases were $1 \%$ formic aqueous solution (A) and acetonitrile (B). The gradient program was: 0 to $5 \mathrm{~min}$, isocratic at $5 \% \mathrm{~B} ; 5$ to $10 \mathrm{~min}$, gradient from 5 to $30 \% \mathrm{~B}$; 10 to $15 \mathrm{~min}$, isocratic at $30 \% \mathrm{~B} ; 15$ to $20 \mathrm{~min}$, gradient from 30 to $70 \% \mathrm{~B} ; 20$ to $25 \mathrm{~min}$, isocratic at $70 \% \mathrm{~B} ; 25$ to $35 \mathrm{~min}$, gradient from 70 to $5 \% \mathrm{~B}$, and 12 min to balance (calibrate) the column before each injection. The flow rate was $1.00 \mathrm{~mL} \mathrm{~min}^{-1}$, and the injection volume was $10 \mu \mathrm{L}$.

Full positive MS scan data was obtained with a 70,000 FWHM (full width at half maximum) resolution power (half maximum width) at $\mathrm{m} / \mathrm{z} 200$. For the compounds of interest, a scan range of $\mathrm{m} / \mathrm{z}, 100-1000$ was chosen; the automatic gain control (AGC) was set to $3 \times 10^{6}$ and the injection time set at $200 \mathrm{~ms}$. The scanning speed was set at 2 scans s$^{-1}$. The calibration was performed using a calibration solution in positive and negative modes. For confirmation purposes, a targeted analysis of MS (HCD (higher energy collisional dissociation)) was performed using the mass inclusion list, with a time interval of $30 \mathrm{~s}$, with the Orbitrap spectrometer operating in positive mode..$^{47-49}$

\section{Microorganisms used and absorbance preparation}

The microorganisms used were as follows: Staphylococcus aureus subsp. aureus (American Type Culture Collection (ATCC) 25923), Listeria monocytogenes (ATCC 13932) and Bacillus cereus (ATCC 0299). These strains were reconstituted in brain heart infusion (BHI) broth, with subsequent incubation lasting $24 \mathrm{~h}$ at $37 \pm 2{ }^{\circ} \mathrm{C}$. Subsequently, the inoculation in the selective agars for these microorganisms was carried out (Baird Parker agar, Palcam and Bacillus cereus agars, respectively), for $24 \mathrm{~h}$ at $37 \pm 2{ }^{\circ} \mathrm{C}$. Once the growth of the microorganism was verified, one of the developed colonies was spread on a plate count agar and incubated for $24 \mathrm{~h}$ at $37 \pm 2{ }^{\circ} \mathrm{C}$. A reserve was prepared in $20 \mathrm{~mL}$ of glycerol from the isolated colonies, then subjected to agitation at $200 \mathrm{rpm}$ for $1 \mathrm{~min}$. Then, from each stock of microorganisms, $0.5 \mathrm{~mL}$ aliquots were stored in Eppendorf tubes at $-20^{\circ} \mathrm{C}$. For the reconstitution of the strains used, each Eppendorf tube was refrigerated for $30 \mathrm{~min}$. After this, $10 \mu \mathrm{L}$ of the microorganism was inoculated in glycerol in $5 \mathrm{~mL}$ of BHI and incubated for $24 \mathrm{~h}$ at $37 \pm 2{ }^{\circ} \mathrm{C}$. Finally, suspensions of each microorganism were prepared with absorbance of $0.05,0.1$ and 0.5 , using a spectrophotometer (Thermo Electron Corporation BioMate 5) and employing as a blank, sterile BHI broth. From each of the absorbances the colony-forming units (CFU) were obtained by means of the spread plate method on plate-counting agar and were incubated for $24 \mathrm{~h}$ at $37 \pm 2{ }^{\circ} \mathrm{C}$; these analyses were made in duplicate.

\section{Agar-well diffusion method}

Initially, sterile plates were prepared with $30 \mathrm{~mL}$ of sterile trypticase soy agar (Scharlau, Barcelona, Spain). Then, the inoculation was carried out by using the spreadplating method and adding $100 \mu \mathrm{L}$ of the microorganism to be tested; this had been previously prepared in the chosen absorbance (0.05; 0.5 and 0.1$) .15 \mathrm{~min}$ after inoculation, four equidistant holes of $6 \mathrm{~mm}$ in diameter were made and $50 \mu \mathrm{L}$ of trypticase soy agar was added to each hole. Additionally, a hole was made in the center of the agar to which would be added the solvent minus an extract. After solidification of the agar in each hole, $100 \mu \mathrm{L}$ of the B. pilosa extract with the previously prepared concentration was added. In addition, the central hole contained $100 \mu \mathrm{L}$ of the solvent used (methanol:water in 50:50 ratio). Each Petri dish was incubated at $37{ }^{\circ} \mathrm{C}$ for $48 \mathrm{~h}$. Finally, the inhibition zone diameter $(\mathrm{mm})$ formed around the holes was measured, obtaining the mean value in each plate from the following equation:

$\mathrm{DiH}=\left(\mathrm{D}_{1 / 2}-\mathrm{DO}_{\mathrm{r}}\right)$

where $\mathrm{DiH}$ is the inhibition zone diameter $(\mathrm{mm})$; $\mathrm{D}_{1 / 2}$ is the average diameter in each plate and, $\mathrm{DO}_{\mathrm{r}}$ is the diameter of control hole.

\section{Data processing}

For the optimization of the critical variables of DSASE extraction was used the MODDE software from UMETRICS (Malmö, Sweden) that includes the suggested randomized order in the assay execution, the design of experiments (DOE, center square in the faces) and the multiple linear regression (MLR) model to build the surface responses to advertise the optimal enhancements of performance in the extraction step. In all the cases the analysis of variance (ANOVA) was used as significant criteria for the acceptance of the coefficients in the MLR model. 
For the antibacterial evaluation of the extract against Gram-positive bacteria, a two-factor design was applied. These factors corresponded to the concentration of the extract with 4 levels $\left(100,200,500\right.$, and $\left.1000 \mathrm{mg} \mathrm{L}^{-1}\right)$ and the absorbance of the microorganism with 3 levels $(0.05,0.5$ and 0.1). This design was applied to the 3 microorganisms used and for each one of these, the treatments were performed in sextuplicate, establishing differences through an intersubject effect test with a significance level of $95 \%$. In addition, the origin of these differences was determined by the Tukey's test. Using the SPSS software version $24,{ }^{50}$ the obtained data from the antibacterial evaluation of the extract were analyzed.

\section{Results and Discussion}

\section{Comparison of extraction methods}

For the method optimization of metabolites extracting from the plant, a comparison was made between different SLE extraction methods, Soxhlet, RSDE and DSASE; these techniques were used under similar conditions that have already been mentioned. The analysis was carried out by UHPLC-UV-Vis obtaining the signals corresponding to the molecules present in the extracts (Figure 2). The techniques were evaluated in triplicate and it was obtained an RSD below $5 \%$.

The optimization of the extraction for the DSASE technique has been demonstrated as the most efficient for obtaining the flavonoids studied, followed by the hydrolysis process, shown by the chromatogram (Figure 2). This pressurized dynamic heated solvent extraction was shown to be a powerful technique for these compounds due to the chemical compounds and particles being removed mechanically from the matrix surface and adsorption sites by the shock waves generated. The need for additional sonication depends on the analyte-matrix interaction. Sonication $(20 \mathrm{kHz})$ had positive effects on the recovery of the analytes subjected to DSASE. ${ }^{35,36}$ MODDE Pro 12 program $^{51}$ was used for the optimization process, with which the characteristics of the method were evaluated as analysis factors as shown in Table 1.

Table 1. Critical variables optimization for DSASE extraction

\begin{tabular}{|c|c|c|c|}
\hline Factor & Type & Level & Precision \\
\hline Flow / $\left(\mathrm{mL} \min ^{-1}\right)$ & multilevel & $0.2 ; 0.3 ; 0.5$ & 0.0075 \\
\hline Sample weight / g & multilevel & $0.1 ; 0.3 ; 0.5$ & 0.01 \\
\hline Solvent type & qualitative & $\begin{array}{c}\text { MetOH; EtOH; } \\
\text { MetOH: } \mathrm{H}_{2} \mathrm{O} \\
(1: 1) ; \mathrm{EtOH}: \mathrm{H}_{2} \mathrm{O} \\
(1: 1)\end{array}$ & \\
\hline
\end{tabular}

The program showed, with a linear regression model (MLR), a randomized design of 26 experiments (Table 2) with response variables for the metabolites identified by standards of target analytes. The design was carried out in three blocks with three replicates for each experiment. Randomization and representativeness of the data obtained from each factor is evidenced, with the central points of the

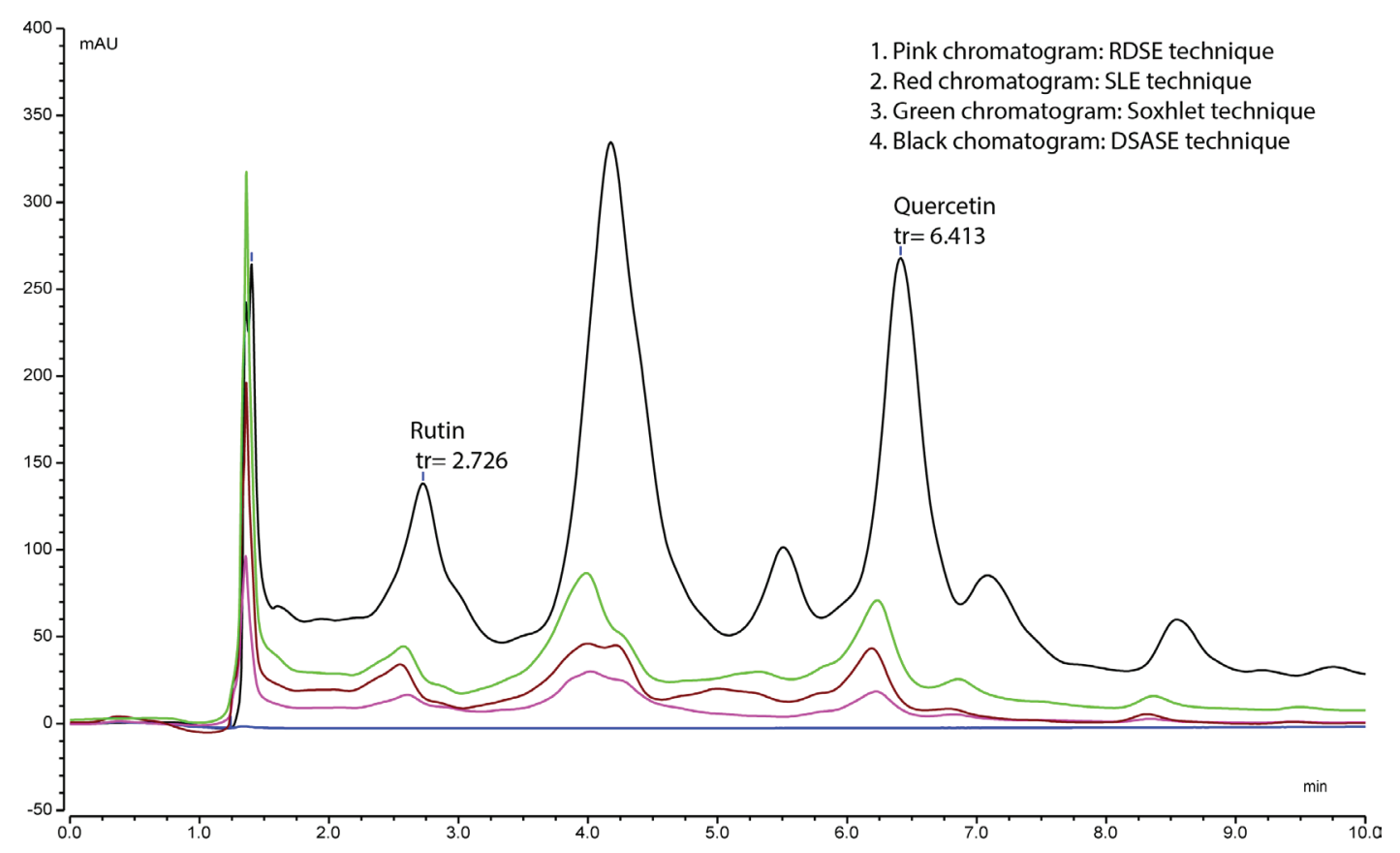

Figure 2. UHPLC-UV overlapped chromatograms of B. pilosa L. extraction by developed methods. 
Table 2. Experimental design for the optimization of extraction by DSASE

\begin{tabular}{|c|c|c|c|c|}
\hline No. & Run order & $\begin{array}{c}\text { Flow / } \\
\left(\mathrm{mL} \mathrm{min}^{-1}\right)\end{array}$ & $\begin{array}{c}\text { Sample } \\
\text { amount / g }\end{array}$ & Solvent \\
\hline 1 & 8 & 0.2 & 0.1 & methanol \\
\hline 2 & 14 & 0.5 & 0.1 & methanol \\
\hline 3 & 3 & 0.3 & 0.3 & methanol \\
\hline 4 & 15 & 0.2 & 0.5 & methanol \\
\hline 5 & 1 & 0.5 & 0.5 & methanol \\
\hline 6 & 22 & 0.2 & 0.1 & ethanol \\
\hline 7 & 2 & 0.5 & 0.1 & ethanol \\
\hline 8 & 16 & 0.5 & 0.3 & ethanol \\
\hline 9 & 9 & 0.2 & 0.5 & ethanol \\
\hline 10 & 21 & 0.3 & 0.5 & ethanol \\
\hline 11 & 12 & 0.5 & 0.5 & ethanol \\
\hline 12 & 7 & 0.2 & 0.1 & methanol/water \\
\hline 13 & 6 & 0.5 & 0.1 & methanol/water \\
\hline 14 & 11 & 0.3 & 0.3 & methanol/water \\
\hline 15 & 20 & 0.2 & 0.5 & methanol/water \\
\hline 16 & 18 & 0.5 & 0.5 & methanol/water \\
\hline 17 & 25 & 0.2 & 0.1 & ethanol/water \\
\hline 18 & 13 & 0.3 & 0.1 & ethanol/water \\
\hline 19 & 4 & 0.5 & 0.1 & ethanol/water \\
\hline 20 & 23 & 0.2 & 0.3 & ethanol/water \\
\hline 21 & 26 & 0.5 & 0.3 & ethanol/water \\
\hline 22 & 5 & 0.2 & 0.5 & ethanol/water \\
\hline 23 & 24 & 0.3 & 0.5 & ethanol/water \\
\hline 24 & 17 & 0.3 & 0.3 & ethanol/water \\
\hline 25 & 19 & 0.3 & 0.3 & ethanol/water \\
\hline 26 & 10 & 0.3 & 0.3 & ethanol/water \\
\hline
\end{tabular}

design. The results were obtained from the average areas of each experiment in a data projection analysis and showed the relationship and importance of the factors.
For the response surface analysis, the optimal conditions for this study are shown and the residuals for each flavonoid have a linear tendency. With regard to the behavior of the experiments, it was concluded that at the usual levels of significance $(0.01<\alpha<0.05)$ the assumption of normality was not rejected by the considered data. The projection for some of the experiments showed the consistency of the favorable conditions for the analytes (Figure 3).

From the response surface analysis (Figure 4), the optimal conditions of the study with a relative standard deviation of $7.5 \%$, together with determination coefficient for quercetin and rutin, 0.84 and 0.93 , respectively, are shown.

The optimal conditions were as follows: flow of $0.3 \mathrm{~mL} \mathrm{~min}^{-1}, 0.5 \mathrm{~g}$ of sample amount and ethanol:water (1:1) as solvent type; the accuracy of the technique was evaluated by means of the recovery percentage in three points of the calibration curve, these corresponded to $86.6 \%$ for quercetin and $85.2 \%$ for rutin $(\mathrm{RSD}<3.0 \%)$.

\section{Chromatographic analysis}

The UHPLC-UV-Vis method for the detection and quantification of flavonoids was standardized with a flow rate of $1 \mathrm{~mL} \mathrm{~min}^{-1}$, an analysis was carried out in a gradient mode starting with 60:40 methanol:water and 40:60 final, with a $10 \mathrm{~min}$ of total run time. The results were as follows: a retention time for rutin was $3.08 \pm 0.15 \mathrm{~min}$ and for quercetin was $6.15 \pm 0.20 \mathrm{~min}$. The figures of merit of developed chromatographic method such as LOD, LOQ, and range linearity (Table 3), were determined from HPLC analysis.

The evidence is that the sensitivity of the chromatographic method for the two metabolites is good, as well as its linearity with the coefficient of determination greater than 0.999 and the resolution of 1.3 and 1.5 for quercetin and rutin, respectively, the construction of the calibration curve presented a linear range in $50-400 \mu \mathrm{g} \mathrm{g}^{-1}$. It can be verified

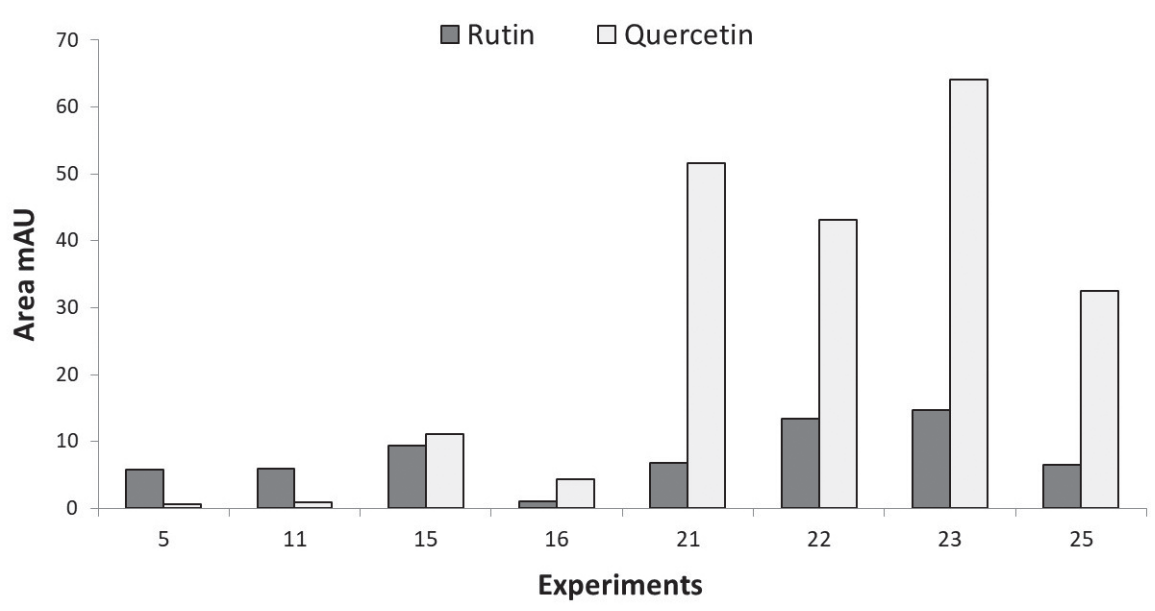

Figure 3. View of the most contrasting experiments of the optimization design. 


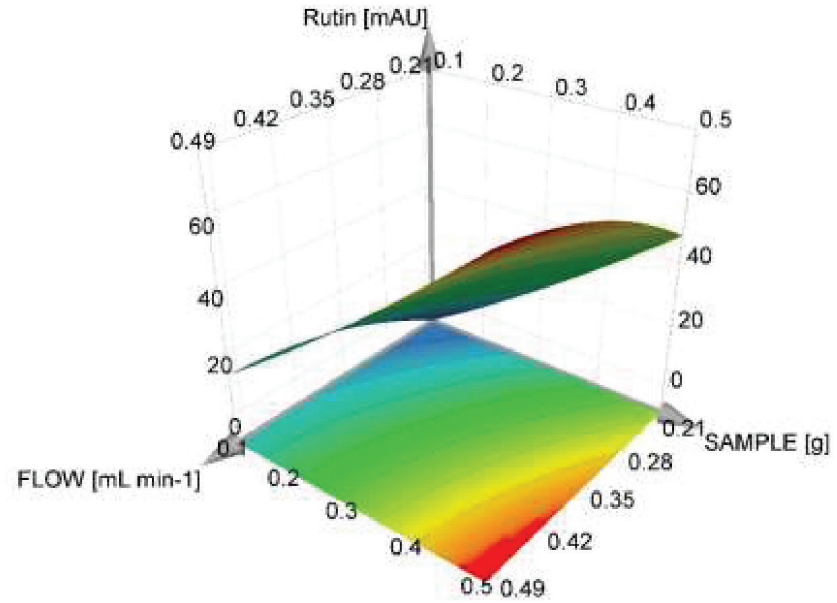

SOLVENT = Etanol_Agua 1_1

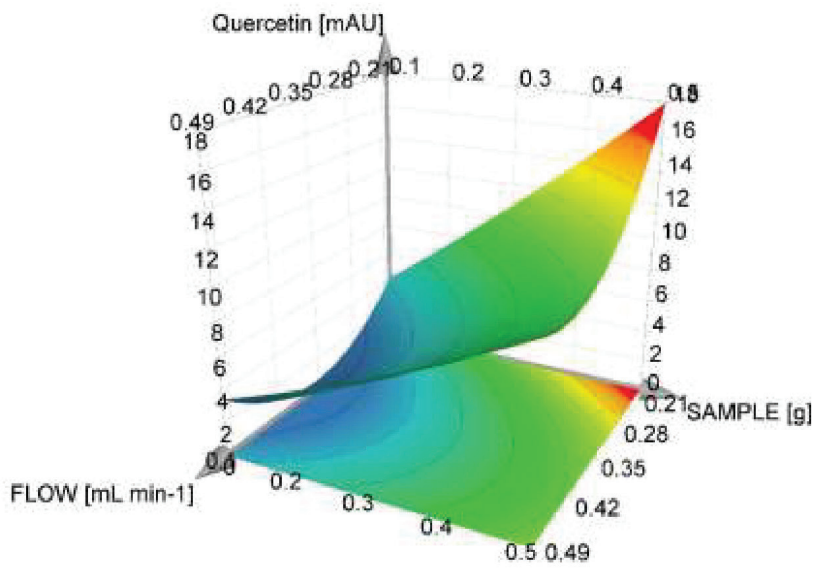

SOLVENT = Etanol_Agua 1_1

Figure 4. Bidens pilosa L. response surfaces for target metabolites by DSASE extraction.

Table 3. Analytical characteristics of the developed method using HPLC UV-Vis

\begin{tabular}{lcccccccc}
\hline Analyte & $\mathrm{t}_{\mathrm{R}} / \mathrm{min}$ & Slope $(\mathrm{m})$ & Intercept $(\mathrm{b})$ & $\mathrm{R}^{2}$ & $\mathrm{~S}_{\mathrm{m}}$ & $\mathrm{S}_{\mathrm{b}}$ & $\mathrm{LOD} /\left(\mu \mathrm{g} \mathrm{g}{ }^{-1}\right)$ & $\mathrm{LOQ} /\left(\mu \mathrm{g} \mathrm{g} \mathrm{g}^{-1}\right)$ \\
\hline Quercetin & $6.15 \pm 0.20$ & 0.486 & 19 & 0.9991 & 0.0074 & 2.2807 & 0.1010 & 10.0672 \\
Rutin & $3.08 \pm 0.15$ & 0.198 & 6.3 & 0.9998 & 0.0015 & 0.3756 & 0.1010 & 10.0556 \\
\hline
\end{tabular}

$\mathrm{t}_{\mathrm{R}}$ : retention time; $\mathrm{R}^{2}$ : determination coefficient; $\mathrm{S}_{\mathrm{m}}$ : standard deviation of slope; $\mathrm{S}_{\mathrm{b}}$ : standard deviation of intercept; LOD: limit of detection; LOQ: limit of quantification.

that the method presented consistency since it presented a value of RSD $<1.5 \%$ for the precision. The developed method with DSASE extraction before UHPLC-UV analysis allowed the quantification of flavonoids present in Bidens pilosa $\mathrm{L}$. in relation to the dry weight of the $0.5 \mathrm{~g}$ of sample of the various parts of the plant (e.g., leaves, flowers) and a mix of both them, which is evidenced in Table 4.

Table 4. Quantification of rutin and quercetin in Bidens pilosa $\mathrm{L}$.

\begin{tabular}{lcc}
\hline Part of plant (extracts $B p \mathrm{~L})$ & Rutin / $\left(\mu \mathrm{g} \mathrm{g}^{-1}\right)$ & Quercetin / $\left(\mu \mathrm{g} \mathrm{g}^{-1}\right)$ \\
\hline Mix & 50.9 & 89.6 \\
Leaf & 5.8 & 11.2 \\
Flower & 118.0 & 107.3 \\
Recovery / \% & 85.2 & 86.6
\end{tabular}

BpL: Bidens pilosa L.

Rutin and quercetin were absent in the plant stem and their concentration were higher in flowers. The whole plant (leaves, stem, flowers) was also analyzed and the major contribution of the flavonoids analyzed was due to the flowers. However, in this study the identity of the molecules by LC-MS analysis was confirmed, verifying especially that the acid hydrolysis was efficient and thus guaranteed the presence of metabolites, especially in the flowers, analysis where they were found in a higher proportion. In the LC-MS analysis, we compared the rutin and quercetin standards with the extract of Bidens pilosa $\mathrm{L}$. flowers (aqueous and organic phases) (Figure 5). It can be shown that in order to identify and quantify the quercetin the acid hydrolysis process was necessary, and the methodology proposed in this work allowed to determine the concentration of quercetin which was not presented in free form in the extract obtained by DSASE.

From the LC-MS analysis it can be determined that the Bidens pilosa L. extract is a source of flavonoids or important antioxidant substances that can be exploited at a phytotherapeutic level. Furthermore, the identity of the analytes studied was verified with a percentage of similarity of $99.9 \%$ for quercetin and $99.9 \%$ for rutin by comparing with standards, together with the characteristic mass fragments (product ions) in this case read in positive mode corresponding to $\mathrm{m} / \mathrm{z}, 70,164,224$ and 303 for quercetin; and $m / z$ 147, 285, 303 and 611 for rutin.

\section{Biological activity}

Effect of the Bidens pilosa L. extract against Gram-positive microorganisms

To obtain an estimated value of the concentration achieved a count was made of each microorganism in 

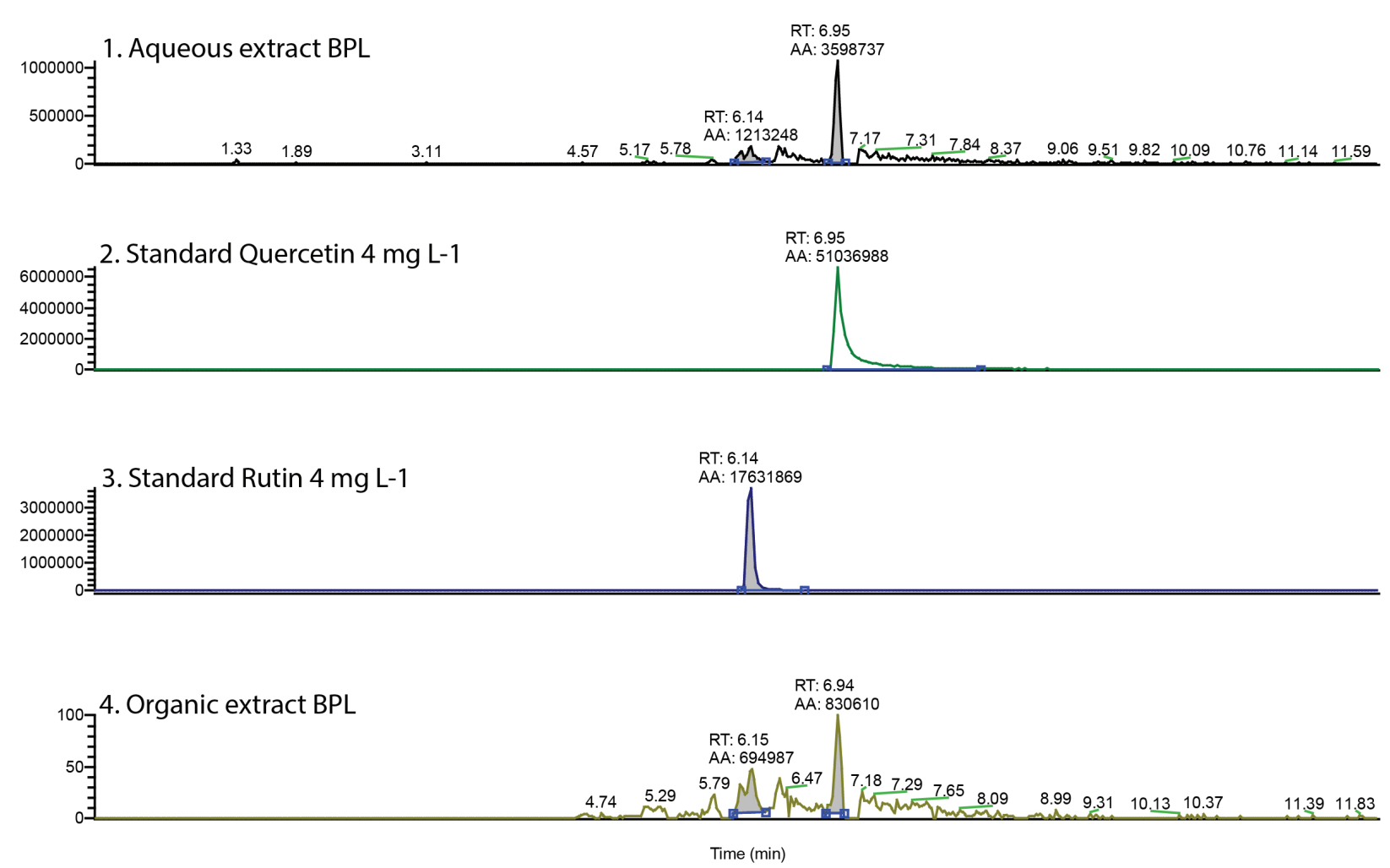

Figure 5. LC-MS chromatograms of aqueous and organics extracts after acid hydrolysis of flower parts of B. pilosa L., and quercetin and rutin standards analyzed by LC-MS Orbitrap.

relation to the average concentrations $(\mathrm{CFU})$ and the absorbances (A) were subsequently subjected to the activity of the Bidens pilosa $\mathrm{L}$. extract. The counts were between $36 \times 10^{10}$ and $29 \times 10^{12}$, with an RSD between $8.9-24.4 \%$ (Table 5).

Table 5. Counts of microorganisms subjected to Bidens pilosa L. extracts from flowers

\begin{tabular}{lccc}
\hline Microorganism & $\mathrm{A}$ & Counts / CFU & RSD / \% \\
\hline \multirow{3}{*}{ S. aureus } & 0.05 & $36 \times 10^{10}$ & 15.7 \\
& 0.1 & $89 \times 10^{10}$ & 19.9 \\
& 0.5 & $51 \times 10^{11}$ & 18.2 \\
\hline \multirow{3}{*}{ L. monocytogenes } & 0.05 & $88 \times 10^{10}$ & 8.9 \\
& 0.1 & $37 \times 10^{11}$ & 13.6 \\
& 0.5 & $72 \times 10^{11}$ & 20.8 \\
\hline \multirow{3}{*}{ B. cereus } & 0.05 & $11 \times 10^{11}$ & 10.3 \\
& 0.1 & $72 \times 10^{11}$ & 17.7 \\
\hline
\end{tabular}

A: absorbance; CFU: colony forming units; RSD: relative standard deviation.

Effect of Bidens pilosa L. extract obtained by DSASE on the $S$. aureus growth

Against the different concentrations of the extract obtained by DSASE, higher means were achieved when the absorbance of the microorganism decreased, and the concentration of the extract was increased. The extract at $1000 \mathrm{mg} \mathrm{L}^{-1}$ allowed a greater inhibition, while the diameters obtained in concentrations of 100 and $300 \mathrm{mg} \mathrm{L}^{-1}$ were similar in the three absorbances used. The inhibitory response throughout the experiment was in the range of 4.08-11.63 mm (Figure 6). Subsequently, the data normality was evaluated by the Shapiro-Wilks test, both for the absorbance datasets $(P>0.05)$ and for concentrations of the extract $(P>0.05)$. In addition, the homoscedasticity of the data was established by a Levene test $(P=0.915)$. After the evaluation of assumptions, the inter-subject effects test was performed which indicated significant differences for both factors, absorbance of $S$. aureus $(P=0.000)$ and extract concentration $(P=0.000)$, no interaction between these factors was observed $(P=0.283)$. Finally, the Tukey's test of multiple comparisons indicated that when increasing the absorbance of the $S$. aureus, a statistically lower mean value in the inhibition diameter was obtained; whereas there was a statistically different effect on the diameter of inhibition of $S$. aureus when increasing the extract concentration; except in the case when 100 and $300 \mathrm{mg} \mathrm{L}^{-1}$ were used, where the means were statistically equal.

Effect of Bidens pilosa L. extract obtained by DSASE on the growth of $L$. monocytogenes

The mean values of the areas of inhibition increased as the absorbance of the inoculum spread with this microorganism 


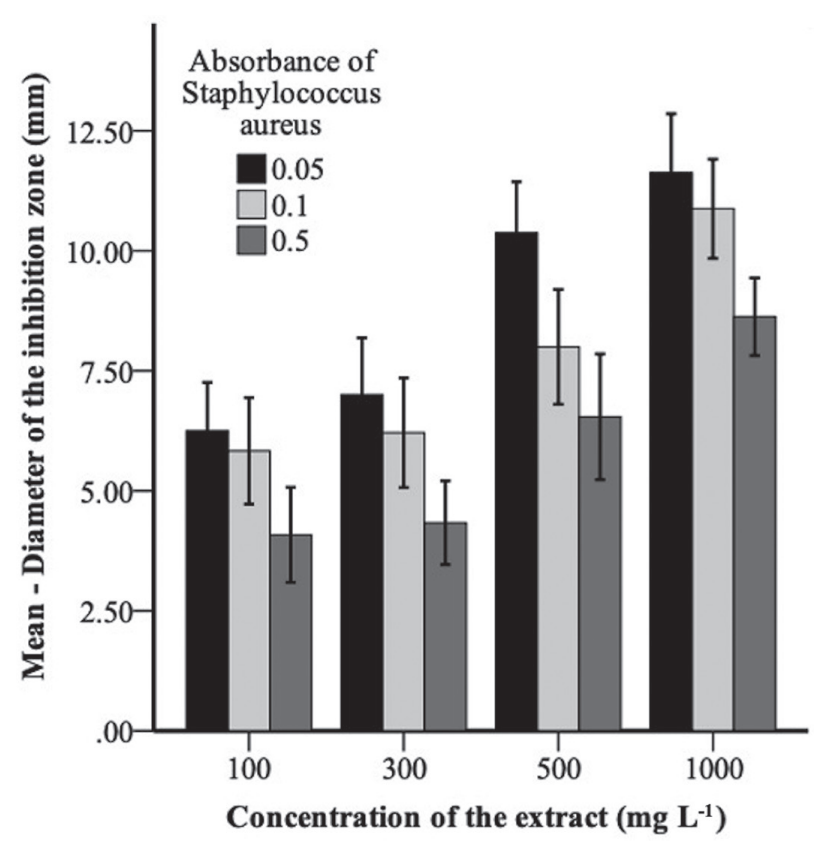

Figure 6. Inhibition of $S$. aureus using the Bidens pilosa L. extract obtained by DSASE.

decreased. Furthermore, the increase in the concentration of the extract triggered higher means of the inhibition diameters, except when a concentration of $300 \mathrm{mg} \mathrm{L}^{-1}$ was supplied, for which, the means were similar to those obtained using the extract at $100 \mathrm{mg} \mathrm{L}^{-1}$, at an absorbance of 0.5. The inhibitory response throughout the experiment was in the range between 2.25 and $7.29 \mathrm{~mm}$ (Figure 7). Regarding the evaluation of statistical assumptions, normality in the datasets for absorbances of the microorganism by the Shapiro-Wilks test was verified $(P>0.05)$ as well as for the datasets corresponding to the concentration of the extract $(P>0.05)$. Similarly, the equality of variances of the data groups was verified $(P=0.912)$. The inter-subject effect test applied to the variable diameter of the zone of inhibition indicated statistical differences among the means obtained by influence of the L. monocytogenes absorbance factors and the Bidens pilosa L. extract concentration $(P=0.00)$; on the other hand, there was no interaction between these factors $(P=0.173)$. Finally, the Tukey's test showed that the increase in absorbance with which L. monocytogenes was spread resulted in a decrease in the mean inhibition diameter obtained, while the increase in the concentration of the extract produced an increase in the mean diameter, except for the lowest concentrations used, specifically, for 100 and $300 \mathrm{mg} \mathrm{L}^{-1}$.

Effect of the Bidens pilosa L. extract obtained by DSASE on the growth of $B$. cereus

When comparing the results obtained for the different absorbances, in all concentrations there was less inhibition

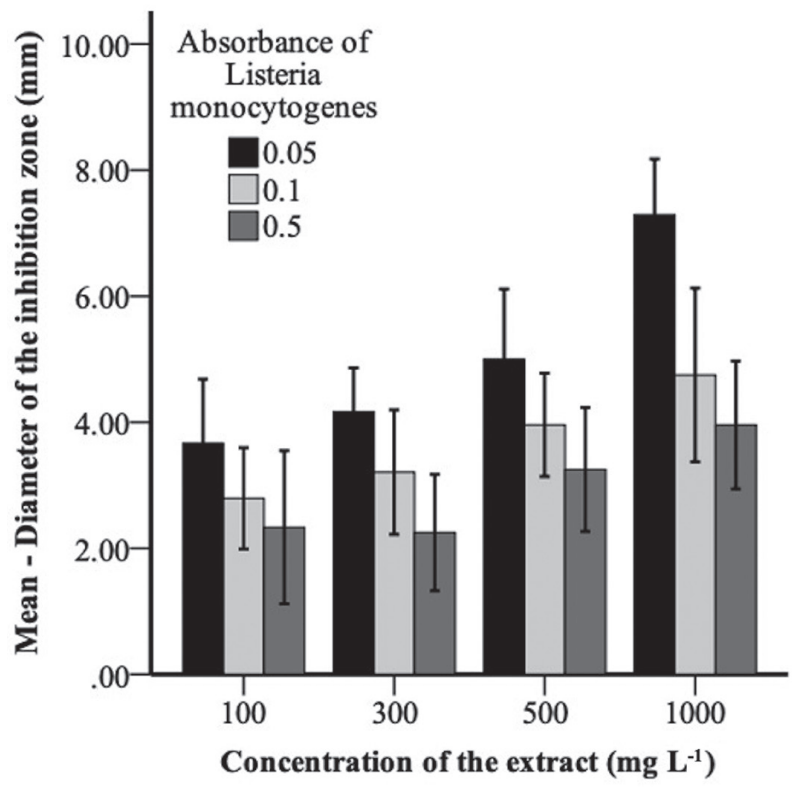

Figure 7. Inhibition of L. monocytogenes using the Bidens pilosa L. extract obtained by DSASE.

when the highest absorbance in the inoculum of B. cereus was used, whereas when using this microorganism in absorbances of 0.05 and 0.1 the mean values of inhibition were similar, except for those obtained at $1000 \mathrm{mg} \mathrm{L}^{-1}$ where the inoculum with 0.05 absorbance allowed a slightly higher inhibition than that obtained with 0.1 . The inhibitory response throughout the experiment was in the range between 6.17 and $13.04 \mathrm{~mm}$ (Figure 8). Subsequently, the Shapiro-Wilk test indicated the normality of the dataset for the variable absorbance of $B$. cereus $(P>0.05)$, as for the variable concentration of the extract $(P>0.05)$. Similarly, the Levene test indicated the homogeneity of the variances for the data related to the diameter of inhibition of B. cereus $(P=0.205)$. Subsequently, the inter-subject effects test was carried out, obtaining differences among the inhibition diameters, for the absorbances used of B. cereus $(P=0.00)$ and the concentrations of the extract of B. pilosa $(P=0.00)$. In addition, there was no interaction between the evaluated factors $(P=0.115)$. Finally, the Tukey's test indicated that the mean obtained at 0.5 absorbance was statistically lower than those obtained with inferior absorbances. Likewise, the diameter of inhibition using $1000 \mathrm{mg} \mathrm{L}^{-1}$ of the Bidens pilosa $\mathrm{L}$. extract was statistically higher than that obtained with lower concentrations, while the extract at $500 \mathrm{mg} \mathrm{L}^{-1}$ allowed diameters statistically higher than those generated with $100 \mathrm{mg} \mathrm{L}^{-1}$, but statistically similar to those obtained using $300 \mathrm{mg} \mathrm{L}^{-1}$.

Some studies ${ }^{47-49}$ had demonstrated the antimicrobial capacity of the extracts of Bidens pilosa L. against $S$. aureus, when ethanol was used as an extraction solvent. In the current study, the mean range against $S$. aureus in 


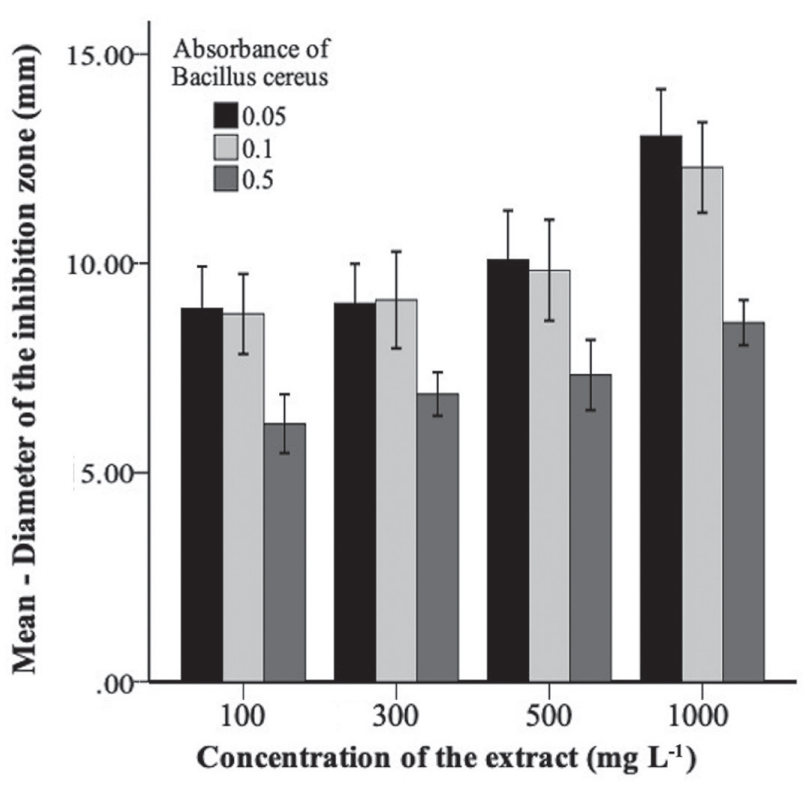

Figure 8. Inhibition of B. cereus using the Bidens pilosa L. extract obtained by DSASE.

the different treatments was between 4.08 and $11.63 \mathrm{~mm}$, similar to the results obtained by other researches. In the study carried out by da Silva et al., ${ }^{7}$ a range between 5 and $15 \mathrm{~mm}$ was obtained by extraction of target metabolites with ethanol. ${ }^{52-55}$ In addition, superior inhibitions have been obtained using exhaustive extraction techniques with distilled water, the inhibition being higher was leaf extract, with a mean of $20.7 \mathrm{~mm} .{ }^{56}$ An additional reference ${ }^{57}$ indicated a mean inhibition range of $26.3 \mathrm{~mm}$ against $S$. aureus when the extract was obtained from the leaves of Bidens pilosa L. The studies where higher inhibitions were obtained have in common the development of exhaustive recovery and concentration stages of the extract, that could promote a differential increase in the inhibition diameter obtained. This could have resulted in a differential increase in the inhibition diameter obtained. With regard to $B$. cereus, most existing references have reported higher inhibitions than those obtained with DSASE in the current study. The activity of leaf extract from Bidens pilosa L. against $B$. cereus ATCC 11778 was also reported ${ }^{7}$ with a mean activity of $18 \mathrm{~mm}$.

In addition, other authors ${ }^{2}$ reported that the antimicrobial activity of the essential oil from $B$. pilosa L. leaves was tested against $B$. cereus, obtaining a mean inhibition diameter of $19.0 \mathrm{~mm}$. Similarly, there was an activity of the $B$. pilosa L. leaf extract against the strain of $B$. cereus ATCC 10876, with an inhibition diameter of $12 \mathrm{~mm} .{ }^{58}$

In contrast, no studies were found about the inhibition of L. monocytogenes by the extract of Bidens pilosa L. The Bidens pilosa L. extract antimicrobial activity against Gram-positive bacteria has various explanations, among them, the content of tannins and saponins presented in this extract. ${ }^{59}$

In addition, a possible relationship with flavonoid compounds and alkaloids that are commonly recovered from different parts of this plant was indicated. ${ }^{7}$ It has been considered that the concomitant presence of phenolic compounds and flavonoids could explain the antimicrobial effect found, other components such as terpenes would have an influence on the triggered effect against B. cereus. Considering the possibility of obtaining polar and non-polar antimicrobial components through the alcoholic extract from Bidens pilosa L., a synergy of these compounds would influence the microbial activity obtained. Another aspect to be considered in terms of the degree of effectiveness produced is the influence of the plant's harvest place and the differential sensitivity of the bacterial strains used in each study. ${ }^{54,55}$

Considering the action mechanism of the bioactive components mentioned above, there are different explanations. ${ }^{59-61}$ On the one hand, the flavonoids would act by coupling with extracellular proteins and with the bacterial wall to promote its deterioration, among which, a derivative of quercetin (quercetin 3,3'-dimethylether$7-O-\beta$-D-glycopyranoside) would participate in the bioactive effect indicated. ${ }^{45,46}$ Another hypothesis of structural damage is the disruption of the membrane by hydrocarbons monoterpenes and oxygenated monoterpenes, resulting in the inhibition of ion transport. ${ }^{2}$

In the case of tannins, these would be involved in enzyme inhibition and the formation of complexes with metal ions to decrease important ions in the metabolic processes of the bacterium. ${ }^{7}$ According to results, it is recommended to study the mechanisms of action of the antimicrobial components from B. pilosa L. such as flavonoids, tannins, and terpenes, recovered individually, in order to understand the specific aspects of its antimicrobial activity against Gram-positive bacteria.

\section{Conclusions}

The novel developed method that included DSASE extraction, UHPLC-UV-Vis analysis and LC-MS corroboration allows the establishment of a system for the detection and quantification of rutin and quercetin metabolites with low detection limits, with an accuracy of $85 \%$ and a high precision ( $\mathrm{RSD}<5 \%$ ). With the optimization of the DSASE extraction method and its

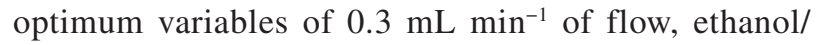
water as type of solvent and $0.5 \mathrm{~g}$ of sample amount for Bidens pilosa L., the quantification of rutin and quercetin enhances the assessment and value of phytopharmaceutical 
potential of Bidens pilosa $\mathrm{L}$. due to the higher concentrations of target metabolites in the flower.

The Bidens pilosa L. extract obtained by DSASE had an inhibitory effect on the growth of $S$. aureus, L. monocytogenes and B. cereus, with higher diameters when using $1000 \mathrm{mg} \mathrm{L}^{-1}$. Furthermore, at an absorbance of 0.05 of these microorganisms in the growth medium used, statistically higher inhibition diameters were obtained with the Bidens pilosa L. extract at concentrations of 500 and $1000 \mathrm{mg} \mathrm{L}^{-1}$. The antimicrobial effect would be related to the presence of various compounds, among them, the phenols and flavonoids found in the methanolic extract used. Subsequent studies could explore the action mechanism of the extract's compounds whilst looking for extraction conditions that promote higher antimicrobial efficacy.

\section{Acknowledgments}

We would like to thank the researchers at the CENIVAM and CROM-MAS laboratories for the academic visit and all their support during the LC-MS analysis of the plant extracts. We also wish to thank the Catholic University of Manizales for its support in the antibacterial evaluation of the extract, and the University of Caldas and the GICTA group for their invaluable contribution during the development of this research.

\section{Author Contributions}

Carlos A. Pinilla was responsible for the conceptualization, investigation and writing original draft; Milton Rosero-Moreano for the conceptualization, resources, writing review and editing; Eduardo J. Corpas for the resources, writing review and editing; Ángela M. López and Andrés F. Gálvez for the investigation; Elena E. Stashenko for the writing review and editing.

\section{References}

1. Akerele, O.; Foro Mund. Salud 1993, 14, 390.

2. Deba, F.; Xuan, T. D.; Yasuda, M.; Tawata, S.; Food Control 2008, 19, 346.

3. Vuorela, P.; Leinonen, M.; Saikku, P.; Tammela, P.; Rauha, J.-P.; Wennberg, T.; Vuorela, H.; Curr. Med. Chem. 2004, 11, 1375.

4. World Health Organization (WHO); Programme on Traditional Medicine; WHO: Geneva, 2002, available at https://apps.who. int/iris/handle/10665/67163, accessed in October 2020.

5. VanPool, C.; Proc. Natl. Acad. Sci. U. S. A. 2019, 166, 11087.

6. de Ávila, P. H. M.; de Ávila, R. I.; dos Santos Filho, E. X.; Bastos, C. C. C.; Batista, A. C.; Mendonça, E. F.; Serpa, R. C.;
Marreto, R. N.; da Cruz, A. F.; Lima, E. M.; Valadares, M. C.; Toxicol. Rep. 2015, 2, 563.

7. da Silva, J.; Cerdeira, C. D.; Chavasco, J. M.; Cintra, A. B. P.; da Silva, C. B. P.; de Mendonça, A. N.; Ishikawa, T.; Boriollo, M. F. G.; Chavasco, J. K.; Rev. Inst. Med. Trop. Sao Paulo 2014, $56,333$.

8. Abajo, C.; Ángeles Boffill, M.; Del Campo, J.; Alexandra Méndez, M.; González, Y.; Mitjans, M.; Pilar Vinardell, M.; J. Ethnopharmacol. 2004, 93, 319.

9. Martínez-Flórez, S.; González-Gallego, J.; Culebras, J. M.; Tuñón, M. J.; Nutr. Hosp. 2002, 17, 271.

10. Bors, W.; Heller, W.; Michel, C.; Saran, M.; Methods Enzymol. 1990, 186, 343.

11. Xuan, T. D.; Khanh, T. D.; J. Pharm. Invest. 2016, 46, 91.

12. Bartolome, A. P.; Villaseñor, I. M.; Yang, W. C.; Evidence-Based Complementary Altern. Med. 2013, 2013, 340215.

13. Lucchetti, L.; Teixeira, D. F.; Barbi, N. S.; Silva, A. J. R.; Rev. Fitos 2013, 4, 60.

14. Kuo, T.-F.; Yang, G.; Chen, T.-Y.; Wu, Y.-C.; Minh, H. T. N.; Chen, L.-S.; Chen, W.-C.; Huang, M.-G.; Liang, Y.-C.; Yang, W.-C.; eFood 2020, 1, 11 .

15. Yi, J.; Wu, J.-G.; Wu, Y.-B.; Peng, W.; Trop. J. Pharm. Res. 2016, 15, 341.

16. Uysal, S.; Ugurlu, A.; Zengin, G.; Baloglu, M. C.; Altunoglu, Y. C.; Mollica, A.; Custodio, L.; Neng, N. R.; Nogueira, J. M. F.; Mahomoodally, M. F.; Food Chem. Toxicol. 2018, 111, 525.

17. Silva, F. L.; Fischer, D. C. H.; Tavares, J. F.; Silva, M. S.; de Athayde-Filho, P. F.; Barbosa-Filho, J. M.; Molecules 2011, 16, 1070 .

18. Chiang, Y. M.; Chuang, D. Y.; Wang, S. Y.; Kuo, Y. H.; Tsai, P. W.; Shyur, L. F.; J. Ethnopharmacol. 2004, 95, 409.

19. Menghinello, P.; Cucchiarini, L.; Palma, F.; Agostini, D.; Dachà, M.; Stocchi, V.; J. Liq. Chromatogr. Relat. Technol. 1999, 22, 3007.

20. Liang, X.; Xu, Q.; J. Sep. Sci. 2016, 39, 1853.

21. Hsu, Y. J.; Lee, T. H.; Chang, C. L. T.; Huang, Y. T.; Yang, W. C.; J. Ethnopharmacol. 2009, 122, 379.

22. Khan, M. R.; Kihara, M.; Omoloso, A. D.; Fitoterapia 2001, 72,662 .

23. Cortés-Rojas, D. F.; Chagas-Paula, D. A.; da Costa, F. B.; Souza, C. R. F.; Oliveira, W. P.; Braz. J. Pharmacogn. 2013, 23, 28.

24. Sundararajan, P.; Dey, A.; Smith, A.; Doss, A. G.; Rajappan, M.; Natarajan, S.; Afr. Health Sci. 2006, 6, 27.

25. Mandal, S. C.; Mandal, V.; Das, A. K.; Essentials of Botanical Extraction: Principles and Applications, vol. 1, $1^{\text {st }}$ ed.; Academic Press: Amsterdam, Netherlands, 2015.

26. Knapp, G.; Oliveira, P. V.; Nóbrega, J.; Flores, É.; Smichowski, P.; Augusto, F.; Pingarrón, J. M.; Zagatto, E. A. G.; Valcárcel, M.; Arruda, M. A. Z. In Trends in Sample Preparation, vol. 1, $1^{\text {st }}$ ed.; Arruda, M. A. Z., ed.; Nova Science Pub Inc.: London, UK, 2007, p. 304. 
27. Williamson, K. L.; Masters, K. M.; Techniques Labs for Macroscale and Microscale Organic Experiments, vol 1, $6^{\text {th }}$ ed.; Cengage Learning: New York, USA, 2011.

28. Armenta, S.; Garrigues, S.; Esteve-Turrillas, F. A.; de la Guardia, M.; TrAC, Trends Anal. Chem. 2019, 116, 248.

29. Raynie, D. E.; Anal. Chem. 2006, 78, 3997.

30. Romanik, G.; Gilgenast, E.; Przyjazny, A.; Kamiński, M.; J. Biochem. Biophys. Methods 2007, 70, 253.

31. Nn, A.; Med. Aromat. Plants 2015, 04, 3.

32. Vieira, C. M. S.; Mazurkievicz, M.; Lopez Calvo, A. M.; Debatin, V.; Micke, G. A.; Richter, P.; Rosero-Moreano, M.; da Rocha, E. C.; J. Sep. Sci. 2018, 41, 4047.

33. Richter, P.; Leiva, C.; Choque, C.; Giordano, A.; Sepúlveda, B.; J. Chromatogr. A 2009, 1216, 8598.

34. Jachero, L.; Ahumada, I.; Richter, P.; Anal. Bioanal. Chem. 2014, 406, 2987.

35. López, Á. M.; Alvarez, E.; Cortés, C.; Rosero-Moreano, M.; Taborda, G.; Garzón, W.; Bernal, H.; Correa, L.; Sci. Chromatogr. 2016, 8, 115.

36. Sanchez, C.; Ericsson, M.; Carlsson, H.; Colmsjö, A.; J. Chromatogr. A 2003, 993, 103.

37. Zhang, B.; Li, X.; Yan, B.; Anal. Bioanal. Chem. 2008, 390, 299.

38. Redfern, J.; Kinninmonth, M.; Burdass, D.; Verran, J.; J. Microbiol. Biol. Educ. 2014, 15, 45.

39. Paz, J. E. W.; Contreras, C. R.; Munguía, A. R.; Aguilar, C. N.; Inungaray, M. L. C.; Braz. J. Microbiol. 2018, 49, 656.

40. Silva, L. L.; Heldwein, C. G.; Reetz, L. G. B.; Hörner, R.; de Moraes, D. P.; Duarte, F. A.; Flores, É. M. M.; Zanella, R.; Pereira, A. M. S.; Heinzmann, B. M.; J. Med. Plants Res. 2015, 9, 199.

41. Cruz Carrillo, A.; Rodríguez, N.; Rodríguez, C. E.; Rev. U.D.C.A Actual. Divulg. Cient. 2010, 13, 117.

42. Sanchez, C.; Ericsson, M.; Carlsson, H.; Colmsjö, A.; Dyremark, E.; J. Chromatogr. A 2002, 957, 227.

43. Miller, J. N.; Miller, J. C.; Miller, R. D.; Statistics and Chemometrics for Analytical Chemistry, vol. 1, $7^{\text {th }}$ ed.; Pearson: London, UK, 2018.

44. González, A. G.; Herrador, M. A.; TrAC, Trends Anal. Chem. 2007, 26, 227.
45. de Boer, T.; Wieling, J.; Bioanalysis 2011, 3, 983.

46. Ramabulana, A. T.; Steenkamp, P.; Madala, N.; Dubery, I. A.; Metabolites 2020, 10, 178.

47. Ajanaku, C.; Echeme, J.; Mordi, R.; Bolade, O.; Okoye, S.; Jonathan, H.; Ejilude, O.; J. Microbiol. Biotechnol. Food Sci. 2018, 8, 721.

48. Singh, G.; Passsari, A. K.; Singh, P.; Leo, V. V.; Subbarayan, S.; Kumar, B.; Singh, B. P.; Lalhlenmawia, H.; Kumar, N. S.; BMC Complementary Altern. Med. 2017, 17, 492.

49. Cortés-Rojas, D. F.; Souza, C. R. F.; Oliveira, W. P.; J. King Saud Univ., Eng. Sci. 2016, $28,141$.

50. SPSS software, version 24; IBM, USA, 2020.

51. MODDE Pro 12; Sartorius, Sweden, 2018.

52. Falowo, A. B.; Muchenje, V.; Hugo, A.; Aiyegoro, O. A.; Fayemi, P. O.; CyTA--J. Food 2017, 15, 249.

53. Chen, Y.; Luo, J.; Zhang, Q.; Kong, L.; J. Funct. Foods 2016, 21, 201.

54. Ashafa, A. O. T.; Afolayan, A. J.; J. Med. Plants Res. 2009, 3 , 568.

55. Owoyemi, O. O.; Oladunmoye, M. K.; Int. J. Mod. Biol. Med. 2017, 8, 24.

56. Deba, F.; Xuan, T. D.; Yasuda, M.; Tawata, S.; Weed Biol. Manage. 2007, 7, 77.

57. Chavasco, J. M.; Prado e Feliphe, B. H. M.; Cerdeira, C. D.; Leandro, F. D.; Coelho, L. F. L.; da Silva, J. J.; Chavasco, J. K.; Dias, A. L. T.; Rev. Inst. Med. Trop. Sao Paulo 2014, 56, 13.

58. Aoudou, Y.; Leopold, T. N.; Michel, J. D. P.; Xavier, E. F.; Moses, M. C.; J. Yeast Fungal Res. 2010, 1, 001.

59. Lawal, I. O.; Grierson, D. S.; Afolayan, A. J.; J. Chem. Inf. Model. 2019, 53, 1689.

60. Kviecinski, M. R.; Felipe, K. B.; Schoenfelder, T.; Wiese, L. P. L.; Rossi, M. H.; Gonçalez, E.; D’arc Felicio, J.; Wilhelm Filho, D.; Pedrosa, R. C.; J. Ethnopharmacol. 2008, 117, 69.

61. Kviecinski, M. R.; Benelli, P.; Felipe, K. B.; Correia, J. F. G.; Pich, C. T.; Ferreira, S. R. S.; Pedrosa, R. C.; J. Supercrit. Fluids 2011, 56, 243.

Submitted: April 16, 2020

Published online: October 26, 2020 